OPEN ACCESS

Edited by:

Marco Roscigno,

Papa Giovanni XXIII Hospital, Italy

Reviewed by:

Giovanni La Croce,

Papa Giovanni XXIII Hospital, Italy

Pietro Pepe,

Cannizzaro Hospital, Italy

*Correspondence:

Shenghua Liu

drfelixliu@163.com

Xudong Yao

yaoxudong1967@163.com

tThese authors have contributed equally to this work

Specialty section: This article was submitted to

Genitourinary Surgery,

a section of the journal

Frontiers in Surgery

Received: 28 May 2021

Accepted: 26 July 2021

Published: 30 August 2021

Citation:

Li C, Wang R, Ma W, Liu S and Yao X (2021) Do Metastatic Kidney Cancer Patients Benefit From Cytoreductive Nephrectomy? A Real-World Retrospective Study From the SEER Database. Front. Surg. 8:716455. doi: 10.3389/fsurg.2021.716455

\section{Do Metastatic Kidney Cancer} Patients Benefit From Cytoreductive Nephrectomy? A Real-World Retrospective Study From the SEER Database

\author{
Cheng $\mathrm{Li}^{1 \dagger}$, Ruiliang Wang ${ }^{1 \dagger}$, Wenchao Ma ${ }^{1,2 \dagger}$, Shenghua Liu ${ }^{1 *}$ and Xudong Yao ${ }^{1,2 *}$ \\ ${ }^{1}$ Department of Urology, Shanghai Tenth People's Hospital, Tongji University School of Medicine, Shanghai, China, \\ ${ }^{2}$ Shanghai Clinical College, Anhui Medical University, Hefei, China
}

Introduction: The benefit of cytoreductive nephrectomy (CN) for metastatic kidney cancer has been challenged recently. The study aimed to evaluate the prognostic roles of surgical resection of primary tumor site for metastatic kidney cancer under a real-world setting.

Methods: The Surveillance, Epidemiology, and End Results (SEER) database (2010-2015) and the overall survival (OS) and cancer-specific survival (CSS) were evaluated using the Cox proportional hazards regression model. One-to-one matching using the propensity score was used to estimate and compare the survival rates.

Results: The SEER data contain records of 8,932 patients from 2010 to 2015. The data showed that $61.7 \%$ of the patients underwent $\mathrm{CN}$ while $38.2 \%$ did not receive any surgery. The median survival month for a patient without surgery was 4 months and for a patient with surgery was 19 months. The multivariate analysis showed that surgical resection of the primary tumor site was an independent favorable predictor for both OS and CSS (all $p<0.001$ ) in the original and the matching cohort.

Conclusions: In the era of target therapy, $\mathrm{CN}$ might still be a vital method to treat metastatic kidney cancer.

Keywords: cytoreductive nephrectomy, metastatic kidney cancer, overall survival, cancer specific survival, SEER

\section{INTRODUCTION}

Kidney cancer remains one of the most commonly diagnosed cancers worldwide. The estimated new cases ranked sixth in men and 10th in women, and $\sim 15 \%$ are metastatic at diagnosis (1). Due to the absence of effective cytotoxic chemotherapy and the radioresistance to renal cell carcinoma (RCC), the prognosis of metastatic renal cell carcinoma ( $\mathrm{mRCC}$ ) is poor and the median survival rate of 1- and 2-year is approximately $10-20 \%$ (2).

The standard of care for metastatic kidney cancer has been under debate over the decades. Cytoreductive nephrectomy $(\mathrm{CN})$ is used to resect the primary tumor in place and single or oligo-metastatic disease. In the era of cytokines (before 2004), the study showed that combining CN with immunotherapy improved overall survival (OS) rate compared with immunotherapy alone, which favored $\mathrm{CN}$ as a standard of care for patient with metastatic disease for a long time $(3,4)$. 
However, since the introduction of vascular endothelial growth factor (VEGF) target therapy in 2004, it has emerged as an important anti-tumor activity with relatively less toxicity $(5,6)$, making CN less important. The role of nephrectomy in treating metastatic kidney cancer has again aroused controversy.

Several meta-analysis and retrospective studies supported CN combined with target therapy instead of target therapy alone $(7,8)$. However, a recent randomized CARMENA study opposed the above review and demonstrated that sunitinib alone was not inferior to sunitinib plus nephrectomy for the primary end point of OS. This again questioned the place of debulking nephrectomy under the background of current tyrosine kinase inhibitor (TKI) therapy (9). Despite the newly released level I evidence, surgical resection of the primary tumor site in mRCC is still an option preferred by many urologists in daily practice.

Thus, this study aimed to investigate the controversial issue again to check whether $\mathrm{CN}$ brought more survival benefits compared with the conservative management of M1 kidney cancer, based on the Surveillance, Epidemiology, and End Results (SEER) database, one of the largest population-based cancer databases. This study is still significant as this topic needs more discussion in a large real-world situation. Furthermore, we performed a 1:1 propensity score matching (PSM) analysis, which is a powerful method to minimize the selection bias, to create a 1:1 matched cohort with well-balanced baseline characteristics.

\section{PATIENTS AND METHODS}

\section{Study Population}

Patients diagnosed with metastatic (M1 stage) kidney parenchyma carcinoma from 2010 to 2015 were identified from the SEER database due to the unavailability of metastasis information before 2010. Kidney parenchyma carcinoma with distant metastasis as the first primary malignancy was the inclusion criterion followed in the study. Information of the distant metastatic organs included the bones, brain, liver, and lungs. As the study aimed to investigate the impact of cytoreductive surgery on patients with kidney cancer, patients without sufficient surgery information and those who only underwent local treatment procedures (electrocautery, laser ablation, photodynamic therapy, or cryosurgery) were excluded. The current study was granted an exemption from the Ethics Review Board in the institution because the SEER program collects data from population-based cancer registries with anonymous information. It is a publicly available database with no human participants involved. Hence, no ethical approval was needed. A detailed description of patient selection is shown in Figure 1.

\section{Clinical Factors and Follow-Up Information} Clinical information was collected, such as demographics (age at diagnosis, gender, and year), tumor characteristics (tumor size, laterality, $\mathrm{T}$ stage, $\mathrm{N}$ stage, histology, bone metastasis status, brain metastasis status, liver metastasis status, and lung metastasis status). Follow-up information was collected, such as survival months, survival status, and cancer-specific survival (CSS) status. The major end point was overall mortality and cancer-specific mortality. The duration of OS and CSS was defined as the time from kidney carcinoma diagnosis to the date of all-cause and cancer-specific death, respectively.

\section{Propensity Score Matching}

The propensity scores were estimated using the logistic regression model that had been established from the factors which potentially affected a decision of treatment modalities: no surgery vs. cytoreductive surgery group. Those factors were age, gender, pathologic $\mathrm{T}$ stage, $\mathrm{N}$ stage, laterality, bone metastasis, brain metastasis, liver and lung metastasis, and histology. With the estimated propensity score, a one-to-one matched cohort was constituted using the nearest-neighbor methods, within a 0.000001 caliper size.

\section{Statistics}

A descriptive study of all the variables was conducted. The patients were divided into a group with no surgery and a group with resection of primary tumor site. Pearson's chisquare test was used to compare the categorical variables between two groups, and the $t$-test was used for continuous parametric variables. Survival curves were estimated using the Kaplan-Meier method. The log-rank test was used to assess significant differences between OS and CSS. The multivariate Cox proportional hazards regression analysis was employed to evaluate the prognostic factors in the original and matched group, and hazard ratios (HRs) along with 95\% confidence interval $(95 \%$ CI) were calculated. Only variables of significance in univariate analysis were put into the multivariate analysis. The differences were considered to be significant if $p<0.05$. The statistical analysis was performed using IBM SPSS version 19.0 (SPSS, IBM company, Armonk, NY, USA).

\section{RESULTS}

\section{Patient Characteristics}

A total of 8,932 patients with metastatic kidney parenchyma carcinoma at the time of diagnosis from 2010 to 2015 were included. The detailed patient characteristics are displayed in Table 1. In the study, only 5,518 (61.7\%) patients underwent surgical resection of the primary tumor site while 3,414 (38.2\%) patients did not receive any surgery. The median age of patients with no surgery and with surgery was 61 and 68 years old, respectively. The median survival month for patients without surgery was 4 months (0-71 months) and for patients with surgery, it was 19 months (0-71 months).

Using the propensity score, the matched cohort composed of 582 patients was constructed Table 1 with 291 patients in the surgery group and another 291 in the no surgery group. There was no significantly different distribution of clinical characteristics between the two groups in the matched cohort. The median survival month for patients without surgery was 7 months (0-67 months) and for patients with surgery was 27 months (0-71 months). 


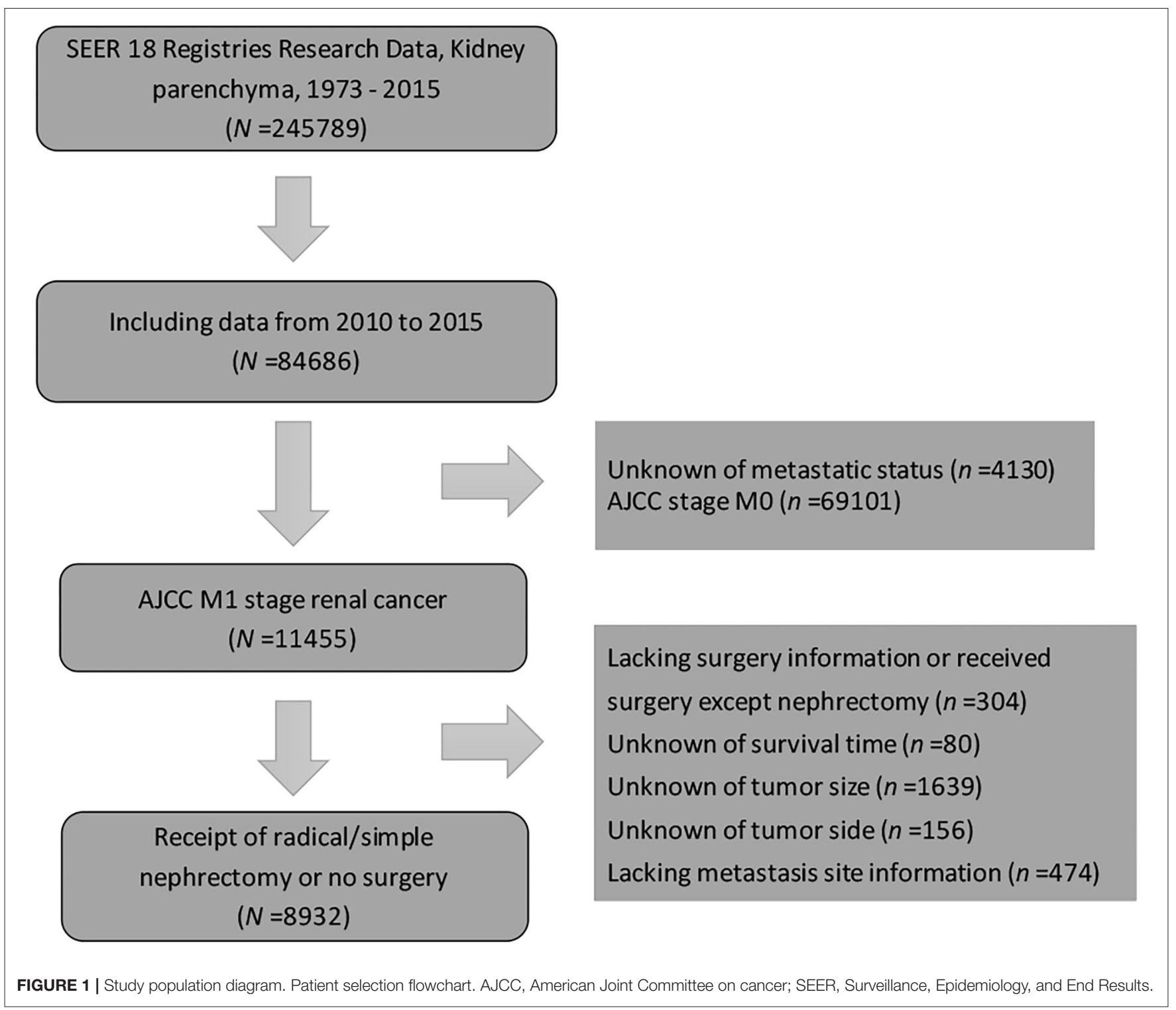

\section{Distribution and Prognosis of Distant Metastatic Sites}

The main metastatic sites of kidney cancer were the bones, brain, liver, and lungs, which composed of 7,891 (88.3\%) of all patients. The information of the four main distant metastatic organs is summarized in Table 2. It was found that 5,465 (61.2\%) patients were diagnosed with lung metastasis, 1,865 (22.2\%) patients with liver metastasis, 3,386 (37.9\%) patients with bone metastasis, and only 999 (11.2\%) patients with brain metastasis. We plotted the distribution of four main metastatic organs in the Venn diagram (Figure 2A). The detailed metastatic sites of patients with more than one organ metastasis are presented in the overlapping area of the Venn diagram.

Those patients with different metastatic sites were extracted separately, and OS was compared between the surgery and no surgery groups. The Kaplan-Meier analysis indicated that patients receiving surgery had OS benefits among those patients with bone metastasis status (Figure 2B), brain metastasis status (Figure 2C), liver metastasis status (Figure 2D), and lung metastasis status (Figure 2E), respectively.

\section{Prognostic Significance of OS}

The 1-year OS rate was $68.9 \%$ for the surgery group and $38.2 \%$ for the no surgery group in the matched cohort $(P<0.001)$. The Kaplan-Meier analysis indicated that patients receiving surgery had OS benefits in both the original and the matched cohort (all $p<0.001$ ) (Figures 3A,C). As shown in Table 3, patients without any surgery maintained a higher risk of mortality compared to the group receiving surgical resection of primary tumor both in the original cohort (HR 2.053, 95\% CI 1.924-2.191, $p<$ 0.001 ) and the matched cohort (HR 2.872, 95\% CI 2.315-3.652, $p<0.001)$. In addition, multivariate analysis showed that older 


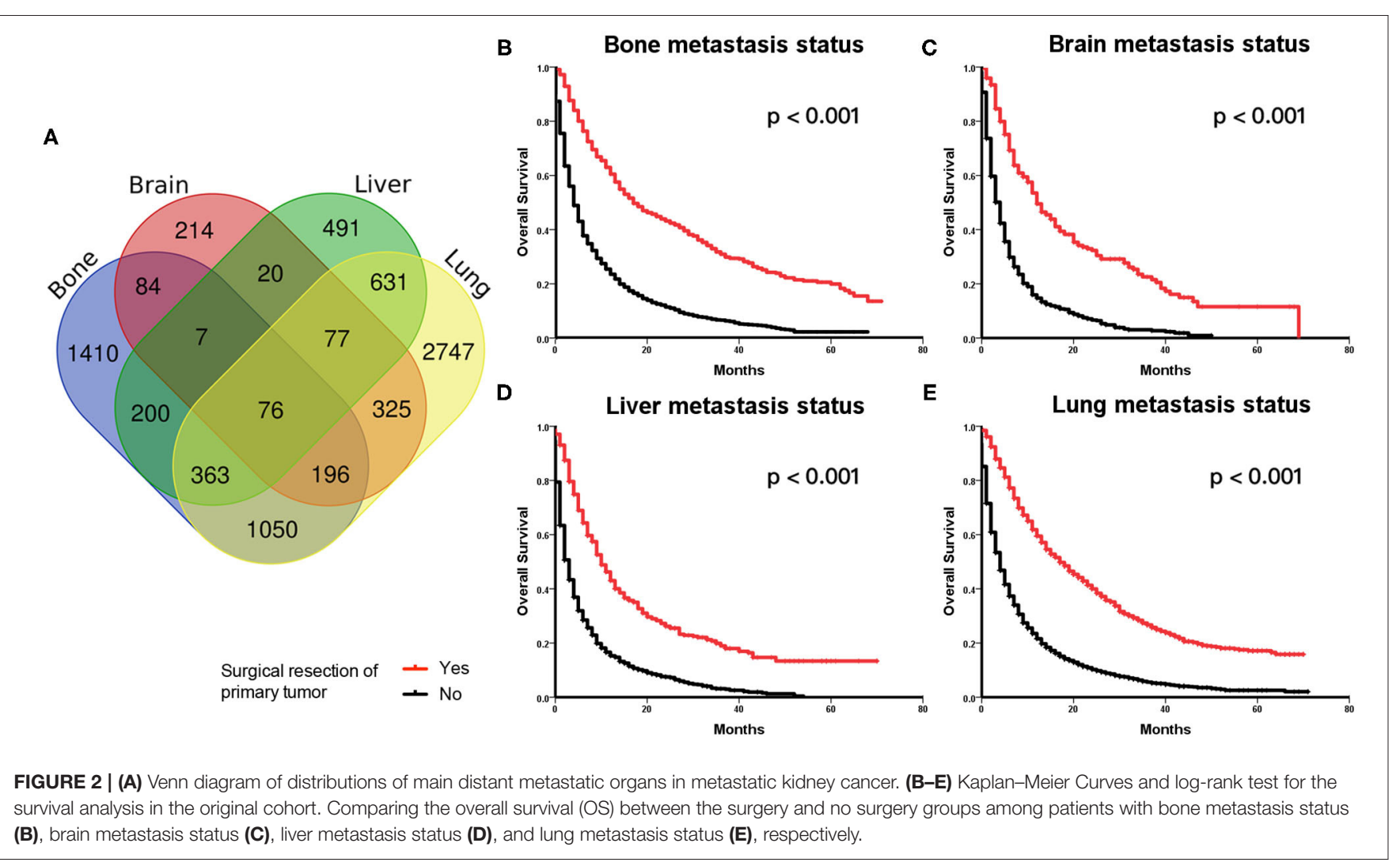

age, late $\mathrm{T}$ or $\mathrm{N}$ stage, presence of distant metastases, and non-clear cell renal cell carcinoma were all unfavorable factors associated with $\mathrm{OS}$ in the original cohort (all $p<0.001$ ). In the matched cohort, tumor on the left side, T4 stage, brain metastasis, and non-clear cell renal cell carcinoma were linked with poorer survival.

\section{Prognostic Significance of CSS}

The 1-year OS rate was $72.6 \%$ for the surgery group and $45.2 \%$ for the no surgery group in the matched cohort $(P<0.001)$. Similarly, patients receiving surgery had better CSS in both the original and the matched cohort (all $p<0.001$ ) (Figures 3B,D). The patients without surgery were associated with an increased risk of mortality compared to the surgery group in the original cohort (HR 2.043, 95\% CI 1.900-2.197, $p<0.001$ ). The trend was also observed in the matched cohort (HR 2.611, 95\% CI 2.050-3.327, $p<0.001$ ). Besides, elderly patients, late $\mathrm{T}$ or $\mathrm{N}$ stage, larger tumor size present of distant metastases, and nonclear cell renal cell carcinoma had significantly decreased CSS in the original cohort in the multivariate results (all $p<0.001$ ). In the matched cohort, only tumor on the left side, T4 stage, brain metastasis, and non-clear cell renal cell carcinoma were associated with poorer CSS (all $p<0.05$ ) Table 4.

\section{DISCUSSION}

In the current study, we first demonstrate the survival advantage of $\mathrm{CN}$ over no surgery for the treatment of M1 kidney cancer using data from the SEER database since 2010. To overcome the selection bias in order to decide the treatment modality (CN vs. no surgery) from retrospective data, a propensity matching score was employed, which is commonly used in large observational studies.

There are various reasons for the gradual decline of $\mathrm{CN}$. Although nephrectomy is a fairly safe procedure, $\mathrm{CN}$ in metastatic kidney cancer still remains a challenge, which is often accompanied with aggressive tumor feature, larger dimension, and severe adhesion to surrounding tissue, making cytoreductive surgery more difficult to perform and increases the risk of complications (10). Another important concern about surgery is that immediate $\mathrm{CN}$ often leads to a significant delay in the onset of systemic therapy, which fails to address the ultimately fatal metastatic disease, leaving its progression uncontrolled. Kutikov et al. (11) found that nearly one-third of patients with mRCC did not receive systemic treatment after $\mathrm{CN}$ and the most common reason was rapid postoperative disease progression. The third is the ubiquitous administration of target medicine in the recent years that lowers the status of surgery, which is strongly supported by the CARMENA trial.

However, in the present study, we found that $\mathrm{CN}$ still demonstrated significant OS and CSS advantages, which was in line with many previous findings $(12,13)$. $\mathrm{CN}$ provided clear survival benefits and has been considered the standard of care until recently for all patients with mRCC (14). One similar real-world cohort study based on the International Metastatic Renal Cell Carcinoma Database found that patients 
TABLE 1 | Patients characteristics between surgery and no surgery group.

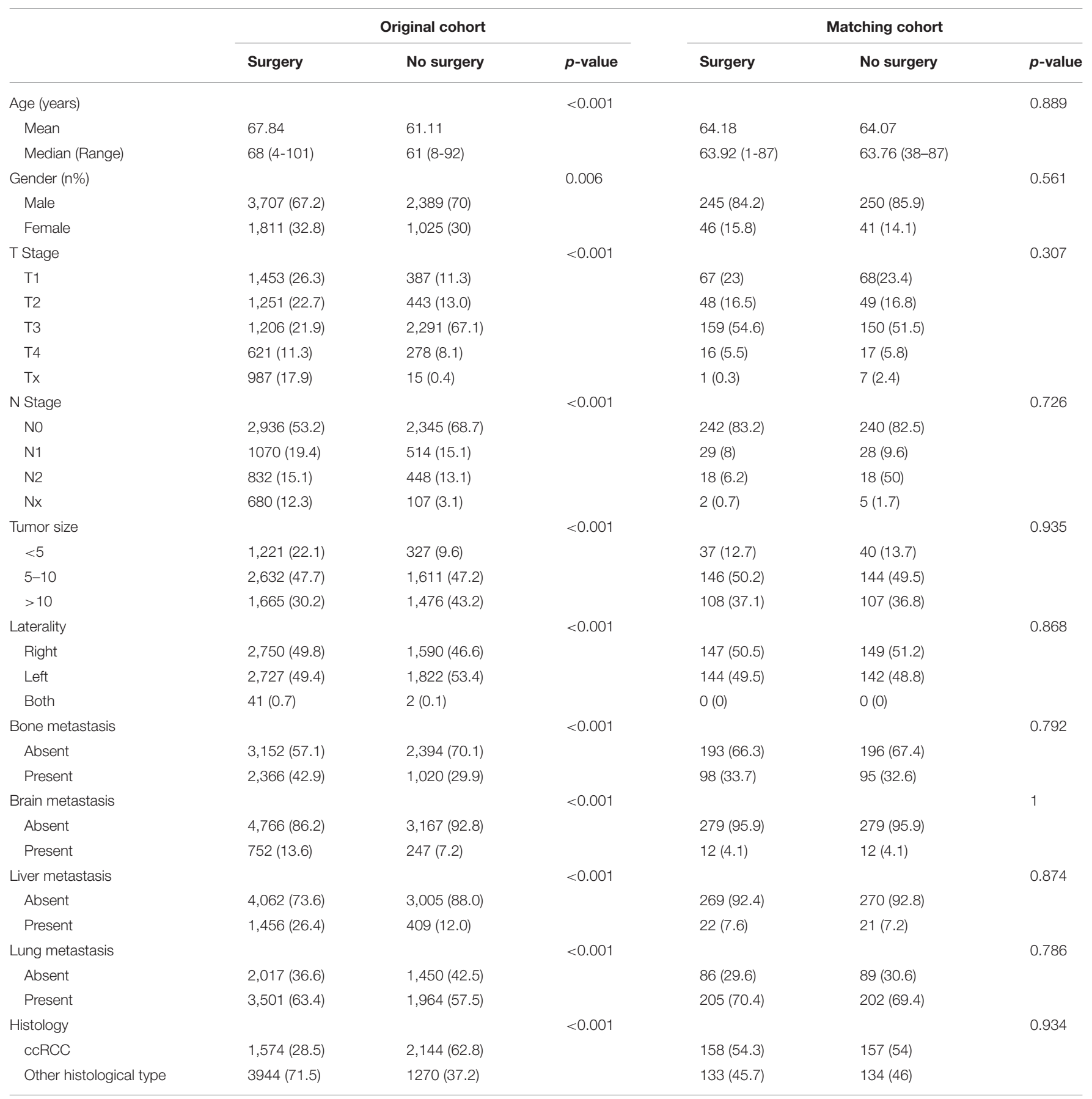

Surgery, the patients underwent cytoreductive nephrectomy; No surgery, the patients did not undergo cytoreductive nephrectomy.

who received CN had better OS than those who did not (15). That is why $\mathrm{CN}$, although a relatedly traumatic therapeutic method, is still accepted by many urologists and patients (16). The potential advantages of $\mathrm{CN}$ are promoting spontaneous regression, reducing the incidence of de novo metastases, or alleviating malignant symptoms (17). Theoretically speaking, removal of large tumor bulk within the kidney may reduce the potential for new aggressive biological clones to develop and thrive (18). Cytoreductive surgery could provide enough samples for the most accurate pathological evaluation, which could guide further drug choice or even new experimental treatments. If cytoreductive surgery is not intended at first, percutaneous biopsy of the primary tumor is commonly recommended to provide histological diagnosis and guide treatment decision (19). However, studies showed that biopsy has its limitations in identifying non-clear-cell histological subtype, sarcomatoid features, or Fuhrman grade (20). Therefore, the role of CN still could not be easily replaced currently. 
TABLE 2 | Characteristics of patients and metastatic organs of original cohort.

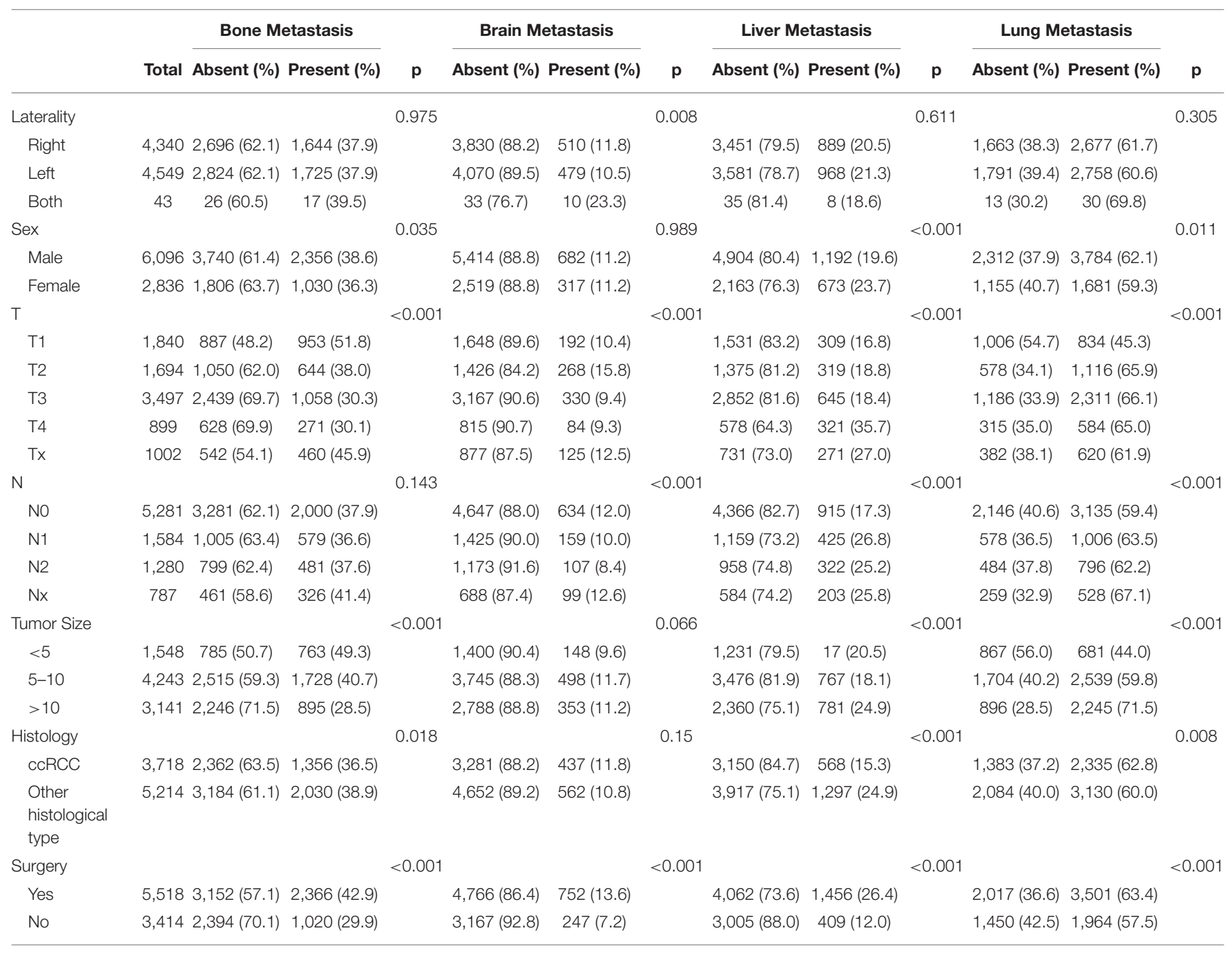

This study showed that there is a huge survival difference between the $\mathrm{CN}$ and no surgery group, no matter in the original ( 19 vs. 4 months) nor the matched cohorts ( 27 vs. 7 months). In CARMENA study, the median OS was 18.4 months for sunitinib alone group vs. 13.9 months in the group starting with nephrectomy followed by sunitinib. The survival discordance could be explained by the difference between a real-world and a well-designed study. Besides, there are still patient selection bias and unbalance between the groups in the CARMENA study. Only intermediate and poor-risk patients were included in a higher proportion of advanced patients, which is the group already known to be least likely to benefit from $\mathrm{CN}$. The points mentioned above might influence the interpretation of the CARMENA results (21). In the McIntosh A.G study, they observed that adverse features of final pathology, such as $\mathrm{pT}$ and $\mathrm{pN}$ stages, lymphovascular invasion, and sarcomatoid and rhabdoid dedifferentiation, were directly related to an increasing number of risk factors. At the same time, the increase of surgical blood loss, postoperative complications, and readmission rates are also associated with high risks (22). However, when 608 patient cohorts were appropriately risk stratified based on the surgical benefit, $\mathrm{CN}$ seemed to predict a survival benefit. The present study reflected that although TKI therapy has been widely used after the year 2010 in the United States, patients receiving $\mathrm{CN}$ still benefit. That is partly because under the real-world setting, there are still a large proportion of patients who do not follow rigid treatment scheme due to economic or social reasons. Some people even quit because of drug adverse event. One more reason is our cohort including patients with not only clear cell carcinoma but also non-clear cell carcinoma histology, which is not so effective for mere VEGF target therapy.

To our knowledge, there are two other similar studies utilizing the SEER database, all showed that patients with mRCC undergoing $\mathrm{CN}$ have improved survival rate in the era of target therapy. Conti et al. enrolling a total of 20,104 patients from 1993 to 2004 , showing that median OS with $\mathrm{CN}$ was 19 months and outweighed 4 months without CN (23). Abern et al. analyzed 2,382 patients from 2005 to 2009 , demonstrating that the patients who underwent $\mathrm{CN}$ had an improved 1-year survival rate (61 vs. $22 \%$ ) (24). In the study, we included patients from 2010 to 2015 
A

OS (Original Cohort)

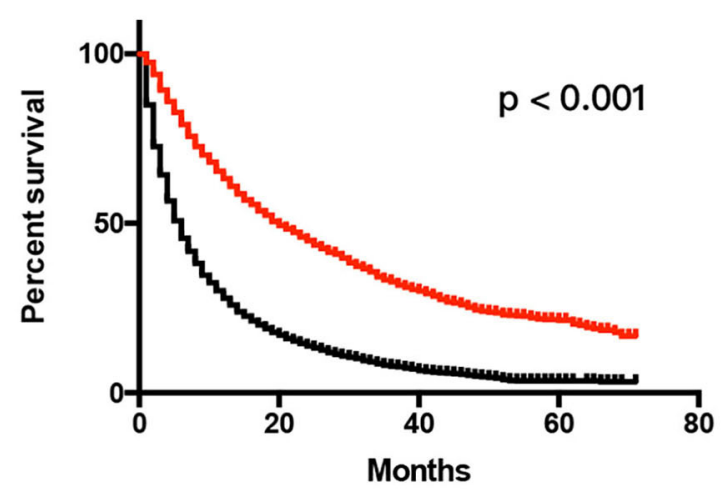
$\begin{array}{ll}\text { Surgical resection of } & \leftarrow \text { Yes } \\ \text { primary tumor } & \perp \text { No }\end{array}$

c

OS (Matched Cohort)

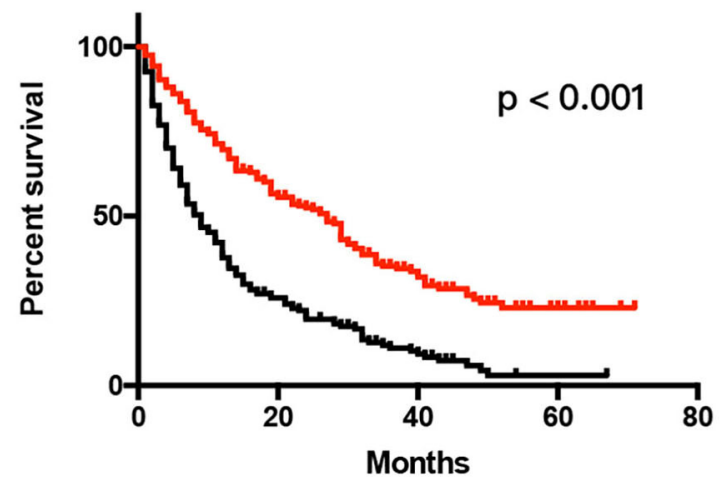

Surgical resection of - Yes

primary tumor $\quad$ No
B

CSS (Original Cohort)

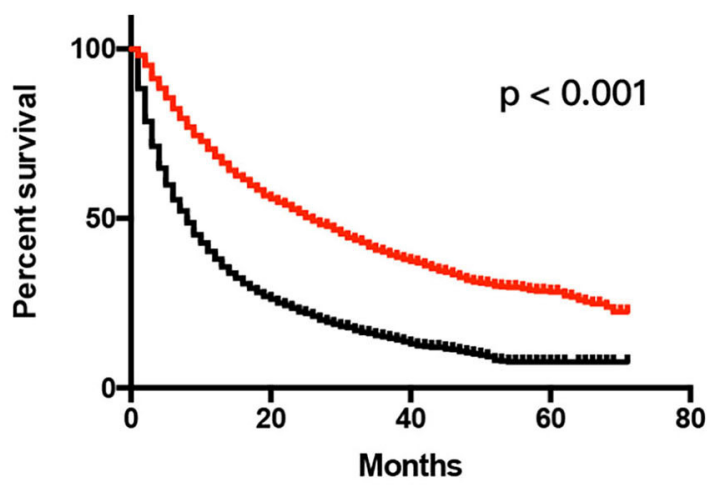

Surgical resection of - Yes primary tumor $\quad$ No

D

\section{CSS (Matched Cohort)}

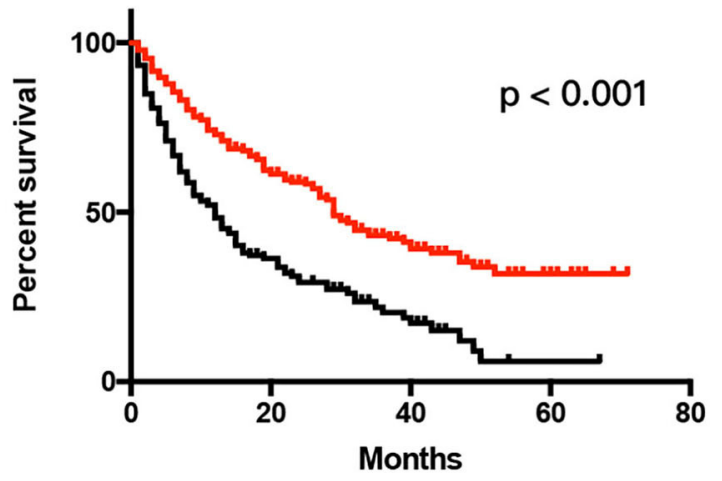

Surgical resection of $\rightarrow$ Yes
primary tumor

FIGURE 3 | Kaplan-Meier Curves and log-rank test for the survival analysis. Comparing OS between the surgery and no surgery groups in the original cohort (A) and the matched cohort (C). CSS was examined in the original cohort (B) and the matched cohort (D). CSS, cancer-specific survival; OS, overall survival.

that could better reflect the current clinical practice. The survival data of this study were almost in line with the previous findings, showing that the outcome did not improve much over time. In Roussel's research, patients most likely to benefit from CN had oligometastatic disease and only had lung metastases (25). In the current study, however, for patients with mRCC with different metastatic sites, such as the bones, brain, liver, and lungs, the surgical group had significantly longer OS than the non-surgical group in the original cohort. Therefore, we are optimistic that most patients with $\mathrm{mRCC}$ can obtain a longer survival period from CN.

Nevertheless, we realized that the current study was limited by the retrospective and non-randomized design. First, although the patients were from a large national database, the systematic treatment information was lacking. There is a group of patients in both the surgical and non-surgical groups who were not eligible for systemic therapy. This could produce bias between the two groups and prevent further interpreting the impact on $\mathrm{CN}$. Second, other physiological indicators related to prognoses, such as lactate dehydrogenase (LDH), serum hemoglobin, albumin, and calcium, were also unavailable in our dataset and might differ between the surgical and no surgical groups (26). Third, the role of $\mathrm{CN}$ nowadays could still be challenging as the therapeutic method of metastatic kidney cancer is progressing rapidly. Compared with traditional cytokine therapy, molecular targeted drugs can significantly improve the objective response rate of patients with $\mathrm{mRCC}$, and prolong progress free survival and OS. Since 2006, the National Comprehensive Cancer Network (NCCN) and the European Association of Urology (EAU) have taken the molecular targeted drugs (sorafenib, sunitinib, temsirolimus, bevacizumab combined with interferon$\alpha$, palipanib, evermus, and axitinib) as first- and second-line 
TABLE 3 | Univariate and multivariate analysis of prognostic factors influencing overall survival.

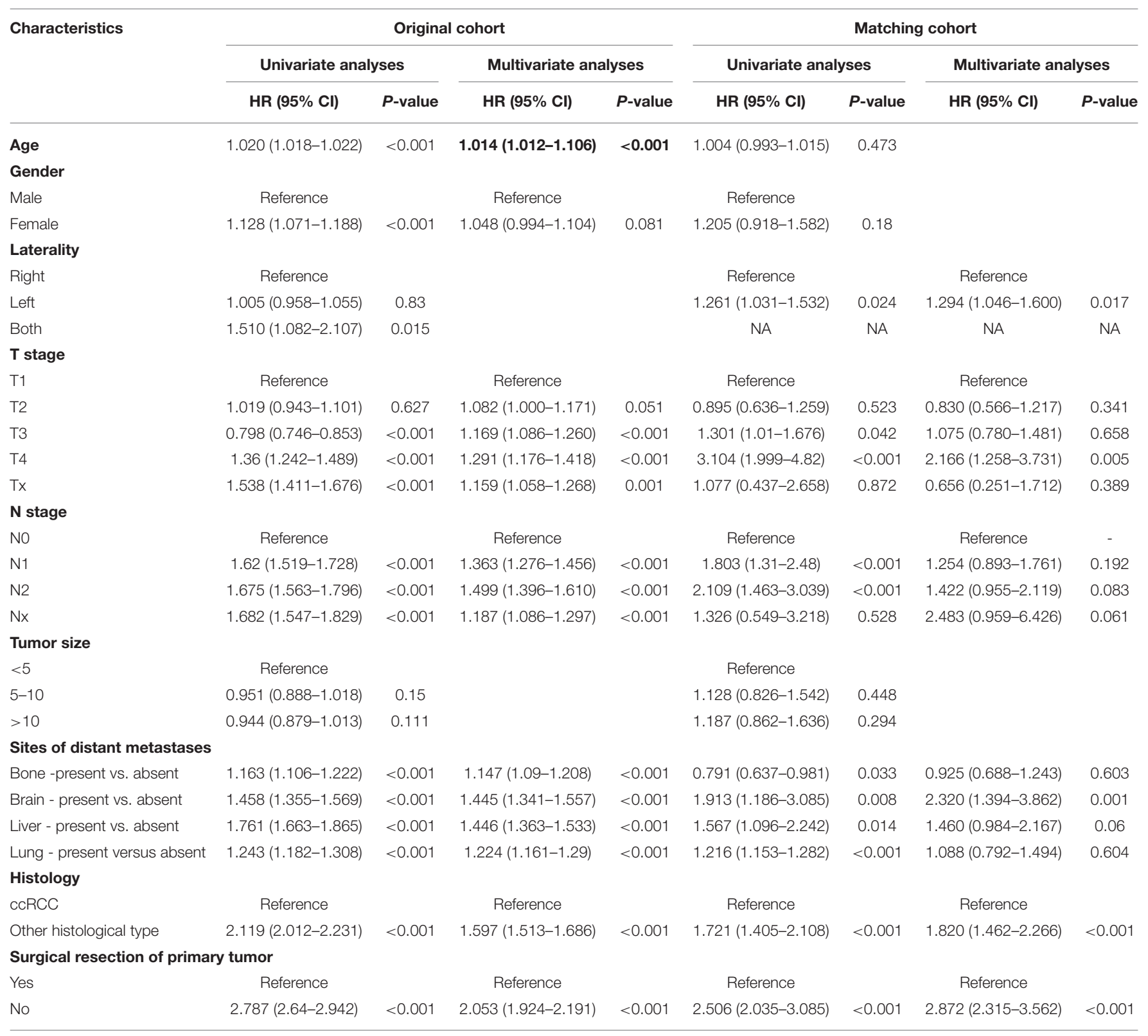

$N A$, not available; HR, hazard ratio; $\mathrm{Cl}$, confidence interval.

treatments for mRCC $(27,28)$. The recent study demonstrated that nivolumab plus ipilimumab has shown significant OS and response rate than sunitinib alone, which enables immune checkpoint blockade to be recommended as frontline therapy in the latest guideline $(29,30)$. A recent real-world study showed that immune-oncology treatment was associated with a better OS in patients who had previously undergone CN (31). Therefore, with the rapid development of systemic treatment of mRCC, a more well-designed randomized study is warranted to investigate the role of $\mathrm{CN}$ under the new era of immune therapy. In addition, clinicians should also carefully evaluate patients using preoperative patient risk stratification tools before offering CN (32).

In a word, the recent study again highlights the importance of surgery for patients with M1 kidney cancer. The optimal choice is to find the most suitable candidate for upfront $\mathrm{CN}$, such as those with good physical condition and limited metastatic tumor burden, to avoid CN or to defer in poor risk patients (33).

\section{CONCLUSION}

Despite newly-emerging pieces of evidence slashing the importance of $\mathrm{CN}$ in M1 kidney cancer, we showed that in the real-world setting, patients undergoing cytoreductive surgery continue to have improved OS compared to those who do not. The optimal sequencing of surgery and systemic therapy warrants further study. 
TABLE 4 | Univariate and multivariate analysis of prognostic factors influencing cancer specific survival.

\begin{tabular}{|c|c|c|c|c|c|c|c|c|}
\hline \multirow{3}{*}{ Characteristics } & \multicolumn{4}{|c|}{ Original cohort } & \multicolumn{4}{|c|}{ Matching Cohort } \\
\hline & \multicolumn{2}{|c|}{ Univariate analyses } & \multicolumn{2}{|c|}{ Multivariate analyses } & \multicolumn{2}{|c|}{ Univariate analyses } & \multicolumn{2}{|c|}{ Multivariate analyses } \\
\hline & HR (95\% Cl) & $P$-value & HR (95\% Cl) & $P$-value & HR $(95 \%$ Cl) & $P$-value & HR $(95 \% \mathrm{Cl})$ & $P$-value \\
\hline Age & $1.01(1.008-1.012)$ & $<0.001$ & $1.007(1.004-1.009)$ & $<0.001$ & $0.995(0.982-1.008)$ & 0.419 & & \\
\hline \multicolumn{9}{|l|}{ Gender } \\
\hline Male & Reference & & Reference & & Reference & & & \\
\hline Female & $1.109(1.046-1.176)$ & 0.001 & $1.059(0.998-1.123)$ & 0.059 & $1.163(0.851-1.588)$ & 0.343 & & \\
\hline \multicolumn{9}{|l|}{ Laterality } \\
\hline Right & Reference & & & & Reference & & Reference & \\
\hline Left & $1.010(0.956-1.067)$ & 0.721 & & & 1.269 (1.010-1.594) & 0.041 & $1.374(1.077-1.753)$ & 0.011 \\
\hline Both & $1.672(1.167-2.397)$ & 0.005 & & & NA & NA & NA & NA \\
\hline \multicolumn{9}{|l|}{ T stage } \\
\hline T1 & Reference & & Reference & & Reference & & Reference & \\
\hline T2 & $1.154(1.055-1.263)$ & 0.002 & $1.035(0.934-1.147)$ & 0.509 & $1.147(0.762-1.726)$ & 0.511 & $0.923(0.563-1.514)$ & 0.75 \\
\hline Т3 & $0.936(0.865-1.012)$ & 0.097 & $1.169(1.063-1.285)$ & 0.001 & $1.766(1.292-2.415)$ & $<0.001$ & $1.324(0.863-2.030)$ & 0.198 \\
\hline T4 & $1.62(1.462-1.795)$ & $<0.001$ & $1.342(1.182-1.484)$ & $<0.001$ & $4.74(2.915-7.705)$ & $<0.001$ & $3.332(1.742-6.373)$ & $<0.001$ \\
\hline Tx & $1.657(1.497-1.833)$ & $<0.001$ & $1.147(1.028-1.280)$ & 0.014 & $1.785(0.712-4.479)$ & 0.217 & $1.012(0.380-2.696)$ & 0.981 \\
\hline \multicolumn{9}{|l|}{ N stage } \\
\hline NO & Reference & & Reference & & Reference & & Reference & - \\
\hline N1 & $1.686(1.568-1.813)$ & $<0.001$ & $1.377(1.278-1.483)$ & $<0.001$ & $1.737(1.203-2.508)$ & 0.003 & $1.247(0.838-1.856)$ & 0.276 \\
\hline N2 & $1.803(1.668-1.949)$ & $<0.001$ & $1.532(1.415-1.659)$ & $<0.001$ & $2.3(1.542-3.429)$ & $<0.001$ & $1.451(0.925-2.275)$ & 0.105 \\
\hline$N x$ & 1.725 (1.569-1.896) & $<0.001$ & $1.208(1.092-1.336)$ & $<0.001$ & $1.379(0.513-3.706)$ & 0.524 & $2.032(0.703-5.878)$ & 0.191 \\
\hline \multicolumn{9}{|l|}{ Tumor size } \\
\hline$<5$ & Reference & & Reference & & Reference & & Reference & \\
\hline $5-10$ & $1.113(1.026-1.208)$ & 0.01 & $1.238(1.132-1.354)$ & $<0.001$ & $1.73(1.145-2.612)$ & 0.009 & $1.574(0.946-2.531)$ & 0.082 \\
\hline$>10$ & $1.182(1.087-1.286)$ & $<0.001$ & $1.317(1.190-1.458)$ & $<0.001$ & $1.856(1.22-2.823)$ & 0.004 & $1.284(0.734-2.249)$ & 0.381 \\
\hline \multicolumn{9}{|c|}{ Sites of distant metastases } \\
\hline Bone -present vs. absent & $1.213(1.147-1.283)$ & $<0.001$ & $1.231(1.161-1.305)$ & $<0.001$ & $0.761(0.595-0.973)$ & 0.03 & $1.105(0.798-1.531)$ & 0.548 \\
\hline Brain - present vs. absent & $1.537(1.416-1.667)$ & $<0.001$ & $1.477(1.362-1.608)$ & $<0.001$ & $2.185(1.313-3.636)$ & 0.003 & 2.729 (1.585-4.699) & $<0.001$ \\
\hline Liver - present vs. absent & $1.8(1.687-1.920)$ & $<0.001$ & $1.448(1.355-1.547)$ & $<0.001$ & $1.713(1.16-2.531)$ & 0.007 & $1.389(0.901-2.139)$ & 0.136 \\
\hline Lung - present vs. absent & $1.316(1.242-1.393)$ & $<0.001$ & $1.253(1.180-1.331)$ & $<0.001$ & $1.556(1.196-2.025)$ & 0.001 & $1.262(0.878-1.816)$ & 0.209 \\
\hline \multicolumn{9}{|l|}{ Histology } \\
\hline ccRCC & Reference & & Reference & & Reference & & Reference & \\
\hline Other histological type & $2.013(1.900-2.133)$ & $<0.001$ & $1.570(1.48-1.671)$ & $<0.001$ & $1.612(1.282-2.028)$ & $<0.001$ & $1.667(1.296-2.143)$ & $<0.001$ \\
\hline \multicolumn{9}{|c|}{ Surgical resection of primary tumor } \\
\hline Yes & Reference & & Reference & & Reference & & Reference & \\
\hline No & $2.589(2.437-2.75)$ & $<0.001$ & $2.043(1.900-2.197)$ & $<0.001$ & $2.322(1.837-2.934)$ & $<0.001$ & $2.611(2.050-3.327)$ & $<0.001$ \\
\hline
\end{tabular}

$N A$, not available; HR, hazard ratio; $\mathrm{Cl}$, confidence interval.

\section{DATA AVAILABILITY STATEMENT}

Publicly available datasets were analyzed in this study. The datasets generated for this study are available in the SEER database (https://seer.cancer.gov/about/overview.html).

\section{AUTHOR CONTRIBUTIONS}

$\mathrm{XY}$ and SL contributed to the conception of the study. RW performed the data curation and analysis. CL and WM wrote the manuscript. WM provided constructive comments to help perform the analysis and participated in the revision of the article. All authors contributed to the article and approved the submitted version.

\section{FUNDING}

The study was supported by the Shanghai Youth Science and Technology Talents Sailing Program (20YF1437200), Shanghai Municipal Health Commission Fund (202040179), and Shanghai Science Committee Foundation (19411967700). 


\section{REFERENCES}

1. Siegel RL, Miller KD, Jemal A. Cancer statistics, 2018. CA Cancer J Clin. (2018) 68:7-30. doi: 10.3322/caac.21442

2. Polcari AJ, Gorbonos A, Milner JE, Flanigan RC. The role of cytoreductive nephrectomy in the era of molecular targeted therapy. Int J Urol. (2009) 16:227-33. doi: 10.1111/j.1442-2042.2008.02245.x

3. Flanigan RC, Salmon SE, Blumenstein BA, Bearman SI, Roy V, McGrath PC, et al. Nephrectomy followed by interferon alfa-2b compared with interferon alfa-2b alone for metastatic renal-cell cancer. N Engl J Med. (2001) 345:16559. doi: 10.1056/NEJMoa003013

4. Mickisch GH, Garin A, van Poppel H, de Prijck L, Sylvester R. European Organization for $\mathrm{R}$, et al. Radical nephrectomy plus interferon-alfabased immunotherapy compared with interferon alfa alone in metastatic renal-cell carcinoma: a randomized trial. Lancet. (2001) 358:966-70. doi: 10.1016/S0140-6736 (01)06103-7

5. Motzer RJ, Hutson TE, Tomczak P, Michaelson MD, Bukowski RM, Oudard $\mathrm{S}$, et al. Overall survival and updated results for sunitinib compared with interferon alfa in patients with metastatic renal cell carcinoma. Am J Clin Oncol. (2009) 27:3584-90. doi: 10.1200/JCO.2008.20.1293

6. Sternberg CN, Davis ID, Mardiak J, Szczylik C, Lee E, Wagstaff J, et al. Pazopanib in locally advanced or metastatic renal cell carcinoma: results of a randomized phase III trial. J Clin Oncol. (2010) 28:10618. doi: 10.1200/JCO.2009.23.9764

7. Bhindi B, Habermann EB, Mason RJ, Costello BA, Pagliaro LC, Thompson $\mathrm{RH}$, et al. Comparative survival following initial cytoreductive nephrectomy versus initial targeted therapy for metastatic renal cell carcinoma. J Urol. (2018). doi: 10.1016/j.juro.2018.03.077

8. Garcia-Perdomo HA, Zapata-Copete JA, Castillo-Cobaleda DF, Role of cytoreductive nephrectomy in the targeted therapy era: A systematic review and meta-analysis. Investig Clin Urol. (2018) 59:2-9. doi: 10.4111/icu.2018.59.1.2

9. Mejean A, Ravaud A, Thezenas S, Colas S, Beauval JB, Bensalah K, et al. Sunitinib alone or after nephrectomy in metastatic renal-cell carcinoma. $N$ Engl J Med. (2018) 379:417-27. doi: 10.1056/NEJMoa1803675

10. Abdollah F, Sun M, Thuret R, Schmitges J, Shariat SF, Perrotte P, et al. Mortality and morbidity after cytoreductive nephrectomy for metastatic renal cell carcinoma: a population-based study. Ann Surg Oncol. (2011) 18:298896. doi: 10.1245/s10434-011-1715-2

11. Kutikov A, Uzzo RG, Caraway A, Reese CT, Egleston BL, Chen DY, et al. Use of systemic therapy and factors affecting survival for patients undergoing cytoreductive nephrectomy. BJU Int. (2010) 106:21823. doi: 10.1111/j.1464-410X.2009.09079.x

12. Tatsugami K, Shinohara N, Kondo T, Yamasaki T, Eto M, Tsushima T, et al. Role of cytoreductive nephrectomy for Japanese patients with primary renal cell carcinoma in the cytokine and targeted therapy era. Int J Urol. (2015) 22:736-40. doi: 10.1111/iju.12803

13. de Groot S, Redekop WK, Sleijfer S, Oosterwijk E, Bex A, Kiemeney LA, et al. Survival in patients with primary metastatic renal cell carcinoma treated with sunitinib with or without previous cytoreductive nephrectomy: results from a population-based registry. Urology. (2016) 95:121-7. doi: 10.1016/j.urology.2016.04.042

14. Biles MJ, Patel HD, Allaf ME. Cytoreductive nephrectomy in the era of tyrosine kinase and immuno-oncology checkpoint inhibitors. Urol Clin North Am. (2020) 47:359-70. doi: 10.1016/j.ucl.2020.04.009

15. Heng DY, Wells JC, Rini BI, Beuselinck B, Lee JL, Knox JJ, et al. Cytoreductive nephrectomy in patients with synchronous metastases from renal cell carcinoma: results from the International Metastatic Renal Cell Carcinoma Database Consortium. Eur Urol. (2014) 66:70410. doi: 10.1016/j.eururo.2014.05.034

16. Staehler M, Battle D, Bex A, Hammers H, George D. Re: Sunitinib alone or after nephrectomy in metastatic renal-cell carcinoma. Eur Urol. (2018) 74:842-3. doi: 10.1016/j.eururo.2018.08.011

17. Singla N, Hakimi AA, Margulis V. Editorial: The evolving role of cytoreductive nephrectomy. Curr Opin Urol. (2019) 29:505-6. doi: 10.1097/MOU.0000000000000653

18. Turajlic S, Xu H, Litchfield K, Rowan A, Chambers T, Lopez JI, et al. Tracking cancer evolution reveals constrained routes to metastases: TRACERx Renal Cell. (2018) 173:581-94. doi: 10.1016/j.cell.2018.03.057

19. Abel EJ, Culp SH, Matin SF, Tamboli P, Wallace MJ, Jonasch E, et al.
Percutaneous biopsy of primary tumor in metastatic renal cell carcinoma to predict high risk pathological features: comparison with nephrectomy assessment. J Urol. (2010) 184:1877-81. doi: 10.1016/j.juro.2010.06.105

20. Abel EJ, Carrasco A, Culp SH, Matin SF, Tamboli P, Tannir NM, et al. Limitations of preoperative biopsy in patients with metastatic renal cell carcinoma: comparison to surgical pathology in 405 cases. BJU Int. (2012) 110:1742-6. doi: 10.1111/j.1464-410X.2012.11124.x

21. Bhanvadia S, Pal SK. Cytoreductive nephrectomy: questions remain after CARMENA. Nat Rev Urol. (2018) 15:530-2. doi: 10.1038/s41585-018-0064-3

22. McIntosh AG, Umbreit EC, Holland LC, Gu C, Tannir NM, Matin SF, et al. Optimizing patient selection for cytoreductive nephrectomy based on outcomes in the contemporary era of systemic therapy. Cancer. (2020) 126:3950-60. doi: 10.1002/cncr.32991

23. Conti SL, Thomas IC, Hagedorn JC, Chung BI, Chertow GM, Wagner TH, et al. Utilization of cytoreductive nephrectomy and patient survival in the targeted therapy era. Int J Cancer. (2014) 134:2245-52. doi: 10.1002/ijc.28553

24. Abern MR, Scosyrev E, Tsivian M, Messing EM, Polascik TJ, Dudek AZ. Survival of patients undergoing cytoreductive surgery for metastatic renal cell carcinoma in the targeted-therapy era. Anticancer Res. (2014) 34:2405-11.

25. Roussel E, Verbiest A, Milenkovic U, Van Cleynenbreugel B, Van Poppel $\mathrm{H}$, Joniau S, et al. Too good for CARMENA: criteria associated with long systemic therapy free intervals post cytoreductive nephrectomy for metastatic clear cell renal cell carcinoma. Scand J Urol. (2020) 54:4939. doi: 10.1080/21681805.2020.1814858

26. Margulis V, Shariat SF, Rapoport Y, Rink M, Sjoberg DD, Tannir NM, et al. Development of accurate models for individualized prediction of survival after cytoreductive nephrectomy for metastatic renal cell carcinoma. Eur Urol. (2013) 63:947-52. doi: 10.1016/j.eururo.2012.11.040

27. Escudier B, Eisen T, Stadler WM, Szczylik C, Oudard S, Siebels M, et al. Sorafenib in advanced clear-cell renal-cell carcinoma. N Engl J Med. (2007) 356:125-34. doi: 10.1056/NEJMoa060655

28. Escudier B, Pluzanska A, Koralewski P, Ravaud A, Bracarda S, Szczylik C, et al. Bevacizumab plus interferon alfa-2a for treatment of metastatic renal c-ell carcinoma:a randomised, double-blind phase III trial. Lancet. (2007) 370(9605): 2103-11. doi: 10.1056/S0140-6736(07)61904-7

29. Atkins MB, Tannir NM. Current and emerging therapies for first-line treatment of metastatic clear cell renal cell carcinoma. Cancer Treat Rev. (2018) 70:127-37. doi: 10.1016/j.ctrv.2018.07.009

30. Motzer RJ, Tannir NM, McDermott DF, Aren Frontera O, Melichar B, Choueiri TK, et al. Nivolumab plus Ipilimumab versus Sunitinib in Advanced Renal-Cell Carcinoma. N Engl J Med. (2018) 378:127790. doi: 10.1056/NEJMoa1712126

31. Stellato M, Santini D, Verzoni E, De Giorgi U, Pantano F, Casadei $\mathrm{C}$, et al. Impact of previous nephrectomy on clinical outcome of metastatic renal carcinoma treated with immune-oncology: A real-world study on behalf of meet-URO group (MeetUro-7b). Front Oncol. (2021) 11:682449. doi: 10.3389/fonc.2021.682449

32. Tabakin AL, Stein MN, Anderson CB, Drake CG, Singer EA. Cytoreductive nephrectomy for metastatic renal cell carcinoma, the ultimate urologic 'Choosing Wisely' campaign: a narrative review. Transl Cancer Res. (2020) 9:7337-49. doi: 10.21037/tcr-20-2343

33. Soares A, Maia MC, Vidigal F, Marques Monteiro FS. Cytoreductive nephrectomy for metastatic renal cell carcinoma: how to apply new evidence in clinical practice. Oncology. (2019) 1-9. doi: 10.1159/000502778

Conflict of Interest: The authors declare that the research was conducted in the absence of any commercial or financial relationships that could be construed as a potential conflict of interest.

Publisher's Note: All claims expressed in this article are solely those of the authors and do not necessarily represent those of their affiliated organizations, or those of the publisher, the editors and the reviewers. Any product that may be evaluated in this article, or claim that may be made by its manufacturer, is not guaranteed or endorsed by the publisher.

Copyright (c) 2021 Li, Wang, Ma, Liu and Yao. This is an open-access article distributed under the terms of the Creative Commons Attribution License (CC BY). The use, distribution or reproduction in other forums is permitted, provided the original author(s) and the copyright owner(s) are credited and that the original publication in this journal is cited, in accordance with accepted academic practice. No use, distribution or reproduction is permitted which does not comply with these terms. 